\title{
ULRIKA WOLF-KNUTS
}

\section{Art, science, and religion}

T hese are the opening words for symposium Art Approaching Science and Religion.

IT IS A GREAT HONOUR TO WELCOME each and every one of you here to Åbo Akademi University. Thanks to the Åbo Akademi University Foundation, the university was established in 1918, which means that it is quite old, taking into consideration that we are in Finland, a country that gained independence only in 1917. However, its roots go back to 1640 when the first university in Finland, then part of the Swedish Kingdom, was founded by the Swedish Queen Christina. After a disastrous fire of 1827 of Turku the university was moved to Helsinki and renamed The Imperial Alexander University, later on Helsinki University.

One of the most influential people at Åbo Akademi University was Amos Anderson (1878-1961), a selfmade, extremely rich man who started out with two empty hands and ended up as a great property owner in Helsinki. He supported Åbo Akademi University in many different ways and as an hommage to him one of the professors here has his chair named after him. The Amoslab of today is one of the fruits emerging from the field of research of the professor; namely art, philosophy and enterprise. Amoslab is very special in its efforts to combine art, scholarship, and science, a fruitful combination, for instance, in town planning, creative economics and sustainability.

But what is common to science and art? Are not scholarship and science strictly administered by steadfast rules? Are not scholarship and science founded on logically proven lines of evidence? Is not the material with which a scholar or a scientist starts his or her analysis very concrete and firm?
And is not art something very free, lacking rules, and something that is created without logic, but with the help of the emotions? Is not the material of an artist very much ad hoc? The scholar and the scientist analyse what there is, but the artist picks what he needs. Is not there a huge difference between these categories of human activity?

In 1950 Johan Huizinga, a Dutch historian and student of culture published a book called Homo ludens. There he introduced the often neglected, diminished and - why not? - mocked concept of play. Man is a creature of play, he stated. According to him play is, among other things, free and it creates order. According to Huizinga play is order.

After having read Huizinga's book I maintain that play is the factor that connects art and science. Art is creative. Play is creative, too. Certainly, according to Huizinga play is gratis. You play for free. Perhaps art is not gratis, but it ought to be free. Art also creates order; however this order can differ from other kinds of order, for instance it often deviates from conventional order. But anyhow there is an aesthetic order in art. Perhaps this is exactly why art captivates so many people.

Scholarship and science have many interfaces with art, but do they connect with play? I would like to answer this question positively. Scholarship and science are creative. A scholar's main task is to find new knowledge. He or she designs the conditions to find this new knowledge. That, per se, is a creative activity, but the way to this new knowledge is even more creative. More often than not a scholar or a scientist trusts intuition when he or she asks where to find this new knowledge. So, the path to new knowledge is the result of a creative process.

Certainly, science and scholarship should be 


\section{ORNAMENT AND BEAUTY}

The artist's feet leave traces in the snow. Their form is beauty - so is their sense: the open meanings of the script, that grow in our minds as through a focussed lens.

In our memories perceptions glow.

The pattern that we see is called a fence but is a boat with oars. Through time we flow, we move from corners, finding space immense.

In art and nature ornaments repeat, but when our movements' circle is complete, we find ourselves in slightly altered places.

Where matter, spirit, art and science meet, creative thinking looks for interfaces. Together our thoughts will form a fleet.

\section{THE TEMPLE OF NON-BEING}

Mount Ararat is looming nearby. The Temple of Non-Being is a place remembering the future that we face. An obelisk is pointing to the sky,

the empty space around it asking: Why? Twelve giant blocks lean round a circle's base over a fire, turning into haze.

The voice of silence can intensify

the presence of the absence of a culture, its body torn to pieces by a vulture, its memory eternal as the soul.

Imagine a reversal: an existence, each particle of life being a hole in emptiness, the base of our resistance. gratis. This is an unrealistic dream. However, it is even more important that scholarship and science should be free, free from religious, political, societal and other demands. Once this was the ideal, but for various reasons this is not possible today, and, regrettably, it is not even the ideal. We have not yet seen the consequences of the recent demands on science and scholarship as servants of society, but from our neighbouring countries in the east and the south we know what they can be. History provides alarming evidence.

Scholarship and science also create order, for by means of new knowledge they fill a gap in the world. Something was missing in the universal jigsaw, but following a scholarly process that piece is no longer missing. Moreover, every one of us knows that scholarship and science have an aesthetic value: a good scholarly study should look like a cigar, and not like a Christmas tree.

Creativity, freedom and order are the characteristics of play, and all of them can be found in both art and scholarship and science. Consequently, play connects art and scholarship-science. This is also the very reason for why it is such a wonderful thing to be an artist or a scholar: to have the opportunity to play all day long!

Ulrika Wolf-Knuts is Professor Emeritus of Folkloristics and the current Chancellor at the Åbo Akademi University.

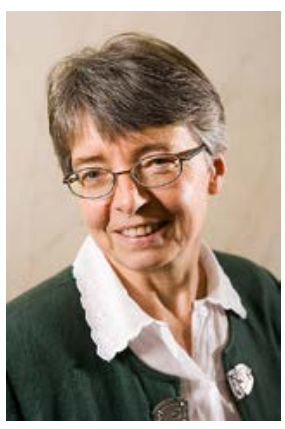

Erik Andersson (Evander) 